UDC 631.31:631.445.4

(C) 2016

V. Medvedev, Academician of the NAAS,

Doctor of Biological Sciences

I. Plisko, O. Bigun,

Candidates of Agricultural Sciences

S. Sheiko, S. Nakisko, S. Krylach, A. Borodin

National Scientific Center "Institute of Soil Science and Agrochemistry named after O.S.Sokolovsky at NAAS of Ukraine

\title{
DEMANDS TO TECHNIQUE AND INSTRUMENTS OF PRESOWING CULTIVATION OF CHERNOZEM SOILS
}

The purpose. On the basis of comparison of real and optimum parameters of structural composition and densities of build in separate underlayers of a root layer to formulate demands to improved techniques and instruments of presowing cultivation of soils. Methods. Field observations, modelling microfield trials, samples and data handling from the data-base "Properties of soils of Ukraine". Results. Over- and underseed layers are enriched with rough structural components (lumps), seed underlayer contains less than $70 \%$ agronomically useful structure that is not enough for formation of favorable water-air and nutritious regimens. Underseed underlayer and plough base flange on the appreciable areas have density of build above $1,3 \mathrm{~g} / \mathrm{sm} 3$ — value which significantly restricts opportunities of the soil to deconsolidate under action of volumetric changes. Conclusions. Main direction of development of technique of presowing cultivation on chernozem soils of loamy granulometric composition is improvement of crumbling of overseed underlayer, accumulation of agronomacally useful structures in seed underlayer and the moderate deconsolidation of soils in underseed underlayer. For presowing cultivation basic new combined instruments capable to recreate optimum model of sowing stratum and do not overstock underseed underlayer and plough base flange are necessary.

Key words: structural composition, density of build, underlayers of root layer, agricultural demands.

\section{Introduction. Having:}

- dedicated a considerable time to studies for influence by soil- structure density and structural composition on crop-plants' genesis, and

- acknowledged the decisive role of these features on seeds' germination and crop-root-system formation (especially during the initial period), 
authors revealed a necessity to supplement the package of now-valid agrotechnical requirements to pre-sowing soil-tillage technologies with these two parameters.

This issue is especially relevant for chernozem soils of loamy texture that dominate all over the Ukrainian Forest Steppe and Steppe zones, where possibilities to adjust values of structural composition and density during pre-sowing period are by far easier than with soils of other particles' size composition [7].

It should be noted that now-valid agro-requirements to technologies and tools for pre-sowing soil-treatment are so far not differentiated in categories of soil types, soilcomposition or crop-plant species, let alone the soil-structure or structural density parameters.

Such a disappointing slip must be corrected undoubtebly.

There is a sound reason to supplement the present-day requirements to presowing technologies and tools with such indicative entries as: soil-structure composition (especially proportion of agronomically usable soil-particles vs coarse lumps); and structural density index, - both as the most important agro-physical parameters.

These features are advantageous for being generally adopted as key properties that greatly influence major soil regimes, and because their optimized parametric values are well known for most of crop species cultivated to-date.

Relying on these soil-property-parameters, it is quite easy to assess effectiveness of any soil tillage technology or agro-tool.

If application of a certain soil tillage technology or a tool results in overcompaction or soil-structure decomposition, such a technology or tool must be expelled from the field-work practice.

These considerations are clearly obvious, yet regretfully, due to various reasons the soil-physical properties (so important factors!) are practically ignored by agromachine/ implement design engineers; absent in characteristics of agro-technical aggregates and agro-tool-specifications, or neglected by agro-machinery manufacturers and consumers. 
Negative impacts on soil (that occur due to such an indifferent attitude from specialists) attract public attention only after dramatic soil-climatic events or their consequences.

Moreover (as evidenced by the long-standing practice of super-heavyweight field-machinery operation in Ukraine), lessons from such negative events are learnt but seldom; and even after adoption of the national Standard on admissible values of loading pressure on soil-cover [11], no positive changes can be seen in the agro-farming reality so far.

It still remains to be regretted that reputation of soil structural density and composition parameters (so much important to highlight specific soil-features) is not recognized by agro-industrial practitioners as yet.

Although these two physical parameters are subject to measurements at certain soil-study R\&D institutions, even there they are not very popular so far; no matter that a century ago, the great Russian soil-explorer Vassiliy V. Dokuchayev had justly pointed out that: “...shortfalls in crops' yield occur rather due to unfavorable physical soilproperties, than because of poor soil-nutrition regime".

Purpose of the article: to formulate agro-requirements to pre-sowing soiltreatment technologies and tools, aground comparative analysis between the factual and optimized values of soil- structure- density and composition- parameters.

Objects and methods of research: Data on factual values of structural density and composition parameters of root-bearing layer across the Forest-Steppe and Steppe chernozems were collected at long-tern observations (as generalized in bibliography references below), and also obtained during the scientific work implemented by the NSC ISSAR in field-test-trial series (2011-2015).

To this end, relevant materials from the NSC ISSAR database "Properties of Soils of Ukraine" [1] were used as well.

Optimized values of these parameters for grain cereal crops cultivation were obtained in model vegetation- and micro-field test-trials launched with use of multifactorial experimentation-planning methods. 
Research results. Certain peculiar features of an approach to determining optimal parameters of physical soil-properties, followed by a generally optimized rootbearing layer-model, have been outlined.

Optimal values of structural composition were determined via the typical "simplex-lattice" method of [composition $\leftrightarrow$ property] planning (in a study for influence on plant- and soil-regimes by structural fractions alone and in mixtures), that guaranteed the most correct resultant data [8].

In order to obtain optimized values of structural density of a sown layer and its supra-seed-, sub-seed- strata; and to derive an optimized model of seed- layer in terms of its structural composition and density parameters, a set of various plans of full- and short- form factorial experiments were involved.

Thus, researchers could apply such plans to 1-, 2-, 3-, 4- and 5-factorial test programs.

Thus abridged plans enabled authors to: shorten variety of options in number (especially in cases with more than 3 factorial variants); automatize data processing routines; facilitate presentation of results and, most important, transform general regularity laws into convenient models, at guaranteed trustworthiness reliability.

Among these test-trial series, the most common type was the micro-field test-trial option conducted upon [1.0 by 1.0-m] (15 - $50 \mathrm{~cm}$-deep) test-plots, whose perimeters were vertically isolated from the ajacent land-sites [8].

Optimal values of structural composition: Experiments have confirmed the popular idea that: “...The higher is percentage of agronomically usable structural aggregates in seed-layer, the richer is the crop-yield harvested".

Thus, the richest crop-yield harvest was recorded after the following preconditions:

\begin{tabular}{|c|c|}
\hline \multicolumn{2}{|c|}{ Content of mixed soil composition } \\
\hline Amount of $5-0.25$ mm particle-size structural \\
aggregates & between 60 to $65 \%$ \\
\hline Amount of coarse lumps & maximum $20-25 \%$ \\
\hline Amount of dusty soil-fraction & maximum $15 \%$ \\
\hline
\end{tabular}


With such the soil-components' ratio, plants-accessible moisture supply was consumed in the most optimal cost-effective regime; plants' transpiration- index was at its minimum; and nutrient elements (from soil and the fertilizer inputs) penerated the crop-roots’ zone quite easily.

It is characteristic that with optimized percentage of structural aggregates, the highest soil-biological activity was registered, alongside reduced rates of nonproductive soil moisture loss caused by physical evaporation.

While maintaining an optimally averaged regime of soil-moisturization at experiments, a certain increase in size of coarse lumps in general soil-composition was noticed, - presumably due to locally insufficient moisture-supply, followed by incomplete penetration of nutrients thereto.

Optimal values of loamy soils' structural density (suitable to the most crop species) range between 1.1 to $1.3 \mathrm{~g} / \mathrm{cm}^{3}$.

These results were obtained aground 35 NSC ISSAR-conducted field test-trials, and after generalization of 45 experiments carried out by relevant soil-researchers.

Regarding crop-plants' responses to values of structural density, the weakest behavior was noted in supra-seed layers, and the most active reaction - in sub-seed layers.

Also noticeable were the crop-plants' responses to values of soil-density in dependence on phases of crops' genesis.

Thus, during seeds' germination and initial phase of roots' formation, plants responded most sensitively to both extra-loosened and over-compacted soils, anyway.

In case of extra-loosened soil, a mighty but ill-productive root system was shaping; whereas under soil-compaction conditions, the root system (though subtlelooking and poorly branched) has shown its prolific viability.

To this end again, various plant-species showed different responses to the croplayer soil-compaction.

Cereal crops were less responsive, contrary to more demanding row-cultivated (especially mini-seed) crop-plants. 
General conclusion finding is that optimal values of physical soil-properties (in spring season) should correspond to:

\begin{tabular}{|l|l|}
\hline \multicolumn{1}{|c|}{ Soil-layer properties } & Structure/density regimes \\
\hline structural density of supra-seed stratum & on the average level \\
\hline structural density of sub-seed stratum & at minimum level \\
\hline soil-structure of seed-sowing layer & in maximum loosened state \\
\hline
\end{tabular}

The long-lasting (of 30 years' diary) research and studies for physical soilproperties have been conducted upon agro-test- facilities of:

- world-known “Askaniya-Nova” Natural Reservation experimental platform (Khersonska oblast; heavy-texture southern chernozem);

- "Mikhailovska” Virgin-Land test-ground (Sumy oblast; typical medium-loamy chernozem);

- "Sinelnikovska” Experimental station (the former 'Ukrainian Maize Institute' in Dnipro- region; typical heavy-loamy lealand chernozem),

have shown that over time (both in years and in seasonal course), values of soilstrucrure density changed but little.

At the same time, values of equilibrium (i.e. steady-state) density of arable land have grown up in all its strata investigated, and especially noticeable - in the plown-pan layer.

As an example, there is a set of results obtained in observations for equilibrium density of root-bearing layer in southern chernozem (Table 1).

1. Values of equilibrium density in main strata of the southern chernozem rootbearing layer, under virgin-land and arable-soil conditions

\begin{tabular}{|l|c|c|c|}
\hline Root - bearing layer strata & $\begin{array}{c}\text { Depth interval, } \\
\mathrm{cm}\end{array}$ & $\begin{array}{c}\text { Virgin land } \\
\text { density, } \\
\mathrm{g} / \mathrm{cm}^{3}\end{array}$ & $\begin{array}{c}\text { Arable soil } \\
\text { density, } \\
\mathrm{g} / \mathrm{cm}^{3}\end{array}$ \\
\hline $\begin{array}{l}\text { supra-seed stratum (without } \\
\text { sod-cover) }\end{array}$ & 0 to 5 & 1.00 & $1.20^{*}$ \\
\hline sub-seed stratum & 10 to 15 & 1.02 & $1.28^{*}$ \\
\hline plown-pan layer & 30 to 35 & 1.17 & $1.34^{*}$ \\
\hline $\begin{array}{l}\text { (*) NOTE: difference in values is truthworthy at } \leq \mathbf{0 . 9 5}\left( \pm \mathbf{0 . 0 4} \mathbf{g} / \mathbf{c m}^{3}\right) \\
\text { allowance }\end{array}$ & probability \\
\hline
\end{tabular}


Using the NSC ISSAR database, results of measurements for equilibrium density parameter were distributed between [0- $5 \mathrm{~cm}$ ] supra-seed stratum; [10- $15 \mathrm{~cm}]$ sub-seed stratum and [30- 35cm] plown-pan layer in Forest-Steppe medium- and heavy-texture soils (Table. 2).

Next, these values were compared to those previously derived as optimized parameters from model experiments.

2. Physical properties of Forest-Steppe medium- and heavy-texrure soils in topand bottom- strata of the root-bearing layer

\begin{tabular}{|c|c|c|c|c|c|c|c|}
\hline \multirow[t]{2}{*}{$\begin{array}{l}\text { Types of soils } \\
\text { investigated }\end{array}$} & \multicolumn{2}{|c|}{$\begin{array}{c}\text { Content of } \\
{[>10 \text { mm]-sized soil }} \\
\text { lumps (\%) }\end{array}$} & \multicolumn{2}{|c|}{$\begin{array}{c}\text { Content of agro- } \\
\text { usable [10-- } \\
0,25 \mathrm{~mm}] \text { soil- } \\
\text { aggrerates (\%) }\end{array}$} & \multicolumn{3}{|c|}{$\begin{array}{l}\text { Equilibrium density }\left(\mathrm{g} / \mathrm{cm}^{3}\right) \text { of soil- } \\
\text { structure }\end{array}$} \\
\hline & $\begin{array}{l}0-5 \mathrm{~cm} \\
\text { deep }\end{array}$ & $\begin{array}{l}\text { 10-15 cm } \\
\text { deep }\end{array}$ & $\begin{array}{l}0-5 \mathrm{~cm} \\
\text { deep }\end{array}$ & $\begin{array}{l}10-15 \mathrm{~cm} \\
\text { deep }\end{array}$ & $\begin{array}{l}0-5 \mathrm{~cm} \\
\text { deep }\end{array}$ & $\begin{array}{l}\text { 10-15 cm } \\
\text { deep }\end{array}$ & $\begin{array}{l}\text { 30-35 cm } \\
\text { deep }\end{array}$ \\
\hline $\begin{array}{l}\text { Dark-grey } \\
\text { chernozems } \\
\text { podzo lized }\end{array}$ & $21,6 / 5$ & $41 / 2$ & $68,9 / 5$ & $54,2 / 2$ & $1,21 / 27$ & $1,32 / 5$ & 1,37/11 \\
\hline $\begin{array}{l}\text { Chernozems } \\
\text { typical }\end{array}$ & $22,4 / 17$ & $25,1 / 17$ & $66,8 / 17$ & $65,5 / 17$ & $1,18 / 30$ & $1,23 / 10$ & $1,27 / 14$ \\
\hline
\end{tabular}

In relevant columns of Table-2, optimal parameters of medium- to heavy-texture soils (used at grain-cereal crops' cultivation) possess the following values:

\begin{tabular}{|l|l|l|}
\hline $\begin{array}{l}\text { Quantity of thick soil particles in supra-seed and } \\
\text { seed layers }\end{array}$ & $\begin{array}{l}\text { in the range between } 0 \text { to } \\
5 \%\end{array}$ \\
\hline $\begin{array}{l}\text { Quantity of agronomically usable soil-structure } \\
\text { particles }\end{array}$ & minimum $70 \%$ \\
\hline Soil-structure density of the sub-seed layer & below $1.2 \mathrm{~g} / \mathrm{cm}^{3}$ \\
\hline & Soil-structure density of the plown-pan layer & maximum $1.3 \mathrm{~g} / \mathrm{cm}^{3}$ \\
\hline
\end{tabular}

Comparison between the real and optimal values of crop layers' physical properties has shown that supra-seed and seed-sown strata are characterized by a certain amount of coarse lumps, resulting in reduced quality of soil- plowing treatment, and more intensive moisture evaporation losses from the arable land. 
The seed-sown layer contains below $70 \%$ of the agronomically usable structure, which is not enough to natural onset of favorable water-air and soil-nutrient regimes.

Especially in arid-season years, values of sub-seed layer- density often exceed $1.3 \mathrm{~g} / \mathrm{cm} 3$, and this fact does significantly inhibit soil's feasibility to discompact itself under volumetric change conditions.

It has been proven that with such values of density, the roots-protrusion and moisture-penetration into consolidated soil-aggregates are back-stopped, and this factor significantly inhibits the soil- loosening transformations.

No doubt, it is exactly the plown-pan stratum where the soil-compaction events are accumulated, thus providing pre-conditions for a long-time overcompaction in active part of the root-bearing layer.

The duly conducted research for influence of soil-treatment tools on values of structural composition and density parameters in seed layers of various soil- types has shown that factual indicators of all present-day subsurface blade- and disk- type tillers somewhat deviate from optimal values.

Agro-requirements to soil-crumbling conditions. Traditionally at pre-sowing period, soil lumps undergo crumbling agro- procedure whose resultant quality varies in a broad scope.

Depending on design features of soil-tillage work-tools or implement, amount of moisture-supply during the soil-treatment time and many other relevant circumstances, one and the same type of soil responds to crumbling-attack in different manners.

With time, the soil-tilled layer acquires various forms of soil-structure, ranging from heavy clods (being conceptually not acceptable for agro-farming practice), to agronomically usable optimumally structurized fine lumps.

Among all causes of different soil-crumbling behaviors in arable lands of Ukraine, the major attribute is a wide variability of aggregation factors (i.e., content of fine-dispersion organo-mineral portions), and polyvalent cations as well.

These factors determine variability of structural composition-characteristics of arable soils. 
Hence, structure of various soil types after harrow- and disking- tillage should be different.

At the same time, agro-requirements to various soil-treatment techniques have never been differentiated in dependence on regional peculiatities as yet.

An idea that soil would readily crumble into good quality-particles anywhere, regardless of soil-climatic conditions, is a non-argumentable error.

Let us mention regretfully that due to now-valid agro-requirements, index of soilcrumbling quality is assessed per quantity of $4-6 \mathrm{~cm}$-sized soil-lumps.

Thus for cultivation, the now-valid soil-standard allows a presence of coarse lumps (though in limited quantity of maximum 5 pieces per square meter).

However, after harrowing procedure, presence of coarse $(>4-6-\mathrm{cm})-$ sized lumps is not allowed at all $[5,9,10]$.

However, let's note that this is the highest the strictest mark.

With a more liberal attitude to the quality of field work procedures, lumps' availability is considered as a completely normal field-attribute of soil-treatment campaign.

In the realm of theoretical soil-physics (where category of agronomically usable soil-lumps ranges between 10 to $0.25 \mathrm{~mm}$, which is completely different from values mentioned before in this article), such a primitive assessment is not acceptable,

After numerous studies and due to evidence of decisive influence by structural composition on all soil-regimes (alongside roots' genesis, fertilizers' efficiency, crop yield and soil fertility in general), it is the right time for us to point out a set of somewhat modified agro-requirements to the soil -rumbling parameter.

To begin with, let's mention the conceptual ideas formulated by "patriarchs" of classical agronomy (W.R. Williams, P.A. Kostychev, O.N. Sokolovsky, K.K. Gedroits, N.A. Kaczinsky et al) in regard of agronomically valuable soil-structure.

One of these bright ideas reads: “... It is most important to formulate agrorequirements to pre-sowing tillage procedures so that while germinating, seeds would sensate gratefully the beneficial merits of the structurized soil...” 
Relying on bibliography sources and our own database, let's formulate agrorequirements to soil crumbling-quality at seed- layer preparation:

- value of force applied on soil by the soil-tillage work-tool should be measurable and constrainable within limits of summarized [shear-resistance], [internal friction] and [soil adhesion] indices of agronomically usable-sized soil-aggregates;

- provided if such the requirement is strictly observed, the soil is not subjected to undue comminution, whereby the agronomically usable sized soil-aggregates would retain their structure and internal porosity, which is very important in supply of plantroots with moisture and nutrients;

- value of force applied on soil by the soil-tillage work-tool should be adjustable to comply with degree of soil-moisture during the soil-treatment period (or, to put it more exactly, with value of crumbling-resistance resulted from such a moisture regime);

- moreover (due to well known legacy by P.V. Vershinin [3], KK. Gedroits [4] and and N.A. Kaczynski [6]), soil crumbling-ability should become an important regional-feature parameter, since dimensions of agronomically usable soil-aggregates depend on degree of soil-moisturization;

- the dryer are climatic conditions, the smaller is size of soil-aggregates and, accordingly, more intensive is the crumbling ability;

- however, an increase in force needed to overcome the summarized aggregates' resistance under arid conditions, must for sure be constrained in definite limits, to avoid the topsoil dust-pollination;

- agronomically usable soil-aggregates should be concentrated in sowing layer (or at least where soil particles are in direct contact with plantage-seeds), whereby dimensions of soil-aggregates must not exceed the size of seeds by more than 3 times.

If these conditions come true and the close contact of seeds with soil is ensured, then rapid seed-germination and roots-genesis are guaranteed.

Requirements to values of topsoil layer crumbling-parameter are less strict, since they allow presence of larger size soil-aggregates (though in minimal quantities). 
Realization of thus proposed requirements to the soil-crumbling parameter would significantly improve the structural status of seed- layer's composition and, thus, enhance conditions for plants' genesis during the crops-growth period.

The core essence of these requirements envisages: a control of thick lumpsconcentration via increased intensity of the soil-crumbling process, and a timely prevention of soil-pollination threats.

Fulfillment of these requirements would be, probably, enabled when in the realm of agromechanical engineering, procedures of the soil-crumbling-quality indexmeasurement and regulation become a routine duty.

Novel approaches to handling the soil-crumbling parameter are definitely needed, including:

- combination of active and passive types of soil-crumbling work-tools;

- search for technical means to enhance the quality of crumbling with existing implement (to be supplemented with novel soil-treatment work-tools);

- development of prospective implement with adjustable angle of attack of soilcrumbling work-tools, and

- promotion of new-Millennium progressive innovations.

Allowance of lumps' content in topsoil layer. Due to lack of consensus among soil scientists, agro-machinery design-engineers, stakeholders and agro-farmers in terms of structural soil-components' sizing dimensions; the now-valid agro-standards actually allow a presence of coarse lumps in seed layer.

According to D.I. Burov [2], even a $5 \%$ proportion of coarse lumps (i.e. soilpieces sized over $10 \mathrm{~mm}$ in cross-section) in seed layer can significantly impair: waterair regime in soil (especially under drought-season conditions), quality of sowing procedures, roots' development and crop- leaves' proliferation.

It was the very D.I. Burov [2] whose studies pointed out the urgency to emphasize the then-existing agro-requirements with demand to forbid conditions for presence of coarse lumps in seed layer.

And indeed, whenever at autumn plowing session some percentage of remaining coarse lumps is allowed $(*)$, their availability ob field at spring-sowing campaign is 
unadmittable $(* *)$. Notes: $\left(^{*}\right)$ because in wintertime, the coarse lumps contribute to cumulative snow detention across the fields; and later on, they almost all disappear;(**) due to their tendency to evaporate all soil-accessible moisture from the seed layer.

In addition, coarse lumps deteriorate quality of seeding procedures, and inhibit the sprouts’ proliferation(*), because the tender root sprouts can not penetrate into solid lumps; all resulting in decrease of usable soil-volume. Note: (*) mainly due to high fracturestrength (30-40 $\mathrm{kPa})$ of coarse lumps [8]).

Agro-requirements to soil-structure density. In any soil-climatic and cropgrowing condition, limits of allowable soil-compaction values must never be exceeded.

In Ukrainian Polissya zone, the look-up coefficient-value is $1.71 \mathrm{~g} / \mathrm{cm} 3$; in the Forest-Steppe: $1.25 \mathrm{~g} / \mathrm{cm} 3$; in the Steppe: $1.42 \mathrm{~g} / \mathrm{cm} 3$; since the required degree of aeration (15\%) is well-maintained exactly in such the soil-density conditions [8].

In availability of a definite practical experience in studies for aeration-dynamics indicator throughout the agro-industrial environment, one can state out that in Polissya conditions, the above-mentioned $15 \%$-index is a rather lenient criterion, not very difficult to comply with.

Ever higher values of structural density in this domain are found only in sandy and heavily-gleyed soils, usually never involved in agro-farming activities.

In Ukrainian Steppe areal (and especially in its Forest-Steppe subzone), the situation is somehow different, as there in plown-layers are many soil-types whose equilibrium density values exceed the optimum-specified limits.

The most severely stressed under soil structure-density conditions (right after the sowing campaign) are stages of seed- germination and first- and second-order rootsprouts’ formation.

In the course of roots' branching development, structural-density factor becomes somewhat weaker, but retaining its validity until the crops- harvest season.

Adjustment of structural density is appropriate at pre-sowing period and during the onset of equilibrium soil-density state (especially if the onset-period is short in time; and if values of the equilibrium density exceed their boundary limits).

In terms of "top-to-bottom” differentiation of soil-density values across the rootsbearing profile, the agro-plants behave in different manners, where grain cereals display 
their easy response, contrary to the row crop-plants that demonstrate their negative depth-proportional reaction.

The row crop-plants, moreover, respond more actively to degree of soil-density of row-beds, rather than to that in inter-row spacings.

This means that the soil-tillage work-tools should be able to control and differentiate values of the structural density throughout the entire root-bearing soilvolume, both vertically and horizontally.

Simultaneously, this also promises an advantageous possibility to completely get rid of inter-row soil-loosening routines during the row-crops' growing season (of course provided if all soil-technological and economic considerations would be taken into account).

The "top-to-bottom" distribution of structural density values across the arablelayer profile (prior to the spring crops' sowing campaign), indicates an existence of two peaks of values related to: the sub-seed stratum directly, and the plow-pan layer.

It is quite understandable that, since values of density in the sub-seed stratum and in the plown-pan layer exceed their critical indices, they altogether significantly impair both the soil-properties and the fate of the future crop-yield, which requires eliminating these drawbacks by aid of targeted new generation work-tools.

Authors have to admit that in terms of geographic confluence, effort to link the above-mentioned peaks of density values to definite agricultural areas have given no success.

The peaks' occurrence is likely to depend on weather conditions; methods of presowing soil-treatment(*) and operation of heavyweight field-machinery. Note: (*) because probability of peaks' occurrence in supra-seed and sub-seed strata increases in permament soil- surfacetreatment conditions).

Regretfully, the to-date technologies of field-crop plants' growing do not factually provide for loosening the sub-seed layer after sowing campaign (except for 2phase technology of sod-podzolic soil- treatment set forth by A.M. Malienko [7]), while instead of getting rid of the plown-pan layer at all, the now-valid technologies can only manipulate several preventive procedures. 
It should be emphasized that novel data on values of the sub-seer layer structural density (and their effect on soil-properties, soil-regimes and crop-yields) would enable us to substantially renovate the old-gone traditional beliefs stating that: "...the newlysown seeds should be placed on a dense soil-bed and gently covered with a "fluffy blanket" lof a loose and wet earth" (which existed from the time immemorial, and are still inherently kept to until nowadays).

Thus, these new concepts and data on influence of soil structure density parameter on field -crops' genesis give us a further impetus and confidence in the need for fundamentally novel agro-technologies and soil-treatment implement.

In Ukraine, these issues may become actually relevant to soils of a decent humuscontent, agronomically usable structure and medium-to-heavy granulometric composition.

\section{Conclusions.}

Considering the decisive influence of structural composition and density on airwater-air soils-regime, sprouts-branching and roots' development, these properties should be taken into account in agro-requirements to technologies and design of preplanting soil soil-treatment machinery and implements.

Comparison between the real and optimal values of structural composition and density parameters has shown that long-term exploitation of loamy-texture chernozems (prevailably across the Forest-Steppe and Steppe zones) has eventually resulted in accumulation of heavy coarse lumps in supra-seed- and seed-sown strata; and in compaction of sub-seed and plown-pan layers.

The major guideline to upgrade technologies of pre-planting treatment of the loamy-texture chernozems should be focused on improvement of soil-crumbling ability in the supra-seed seed layer; accumulation of agronomically usable structures in the seed-sown layer, and careful soil-discompaction in the sub-seed layer.

In Ukraine, it is necessary to intensify work-efforts in designing of fundamentally novel combined implements capable of creating an optimized model of the seed layer, alongside innovative soil-tillage machinery and work-tools that would perform on fields without threats of soil-compaction or plown-pan problems.

\section{Bibliography}

1. Database "Soil Properties of Ukraine". Structure and Procedure//[T.N. Laktionova, V.V. Medvedev, K.V. Savchenko et al]. - [2nd. ed.]. - Kharkiv.: ЦТ \#1, 2012. - 150 pps. 
2. Burov D.I.//On Certain Issues of the Theory of processing and its Practical Receptions on Chernozems in RSFSR. Theoretical problems of soil soil-treatment // D.I. Burov//Leningrad: Hydrometeoizdat, 1969. - P. 32-44 pps.

3. Vershinin P.V.//The Solid Phase of the Soil as the Basis of its Physical Regime. Fundamentals of Agrophysics//PV. Vershinin//M .: Fizmatgiz, 1959. - P. 209404 pps.

4. Gedroitz K.K.//On Certain Issues of the Soil Structure and its Agricultural Significance//Experimental Agronomy Institute. -1926. -VT.4, No. 3. - 117-127 pps.

5. Zaika P.M.//The Theory of Agricultural Machines//P.M. Stutterer.//Kharkiv. 'OKO', 2001. - V. 1, Ch. 1. - 444 p.

6. Kaczinsky N.A.//Physics of Soil//Moscow .: 'Higher school', 1965. - 323 pps.

7. Malienko AM//Scientific bases of soil-treatment of sod-podzolic sandy soils of Polissya, Ukraine// - «General Agriculture»/A.M. Malienko - Kyiv., 1997. - 48 pps

8. Medvedev V.V. //Soil-Technological Zoning of Arable Land of Ukraine//V.V. Medvedev, T.N. Laktionova - Kharkiv.: 13th printing-house, 2007. - 395 pps.

9. Methodology for Assessing the Quality of Field Work ("Agronomic Breeding”, Journal of ). - Yoshkar-Ola (Russia), 1968. - 86 pps.

10. Sahakyan D.N.//Quality Control of Mechanized Field Work in Field Farming// - Moscow “Kolos”, 1973. - 208 pps.

11. National Standard of Ukraine//Agricultural mobile technology. Methods of determining the maximum normal stress//DSTU 4977: 2008.//- Kyiv

"Derzhspozhyvstandart: of Ukraine, 2008. - 11 pps. 